\title{
The Amount of Weight Loss Six Months after Bariatric Surgery: It Makes a Difference
}

\author{
Olga Nedeljkovic-Arsenovic ${ }^{a}$ Marko Banovic a, bejan Radenkovic ${ }^{a, c}$ \\ Nemanja Rancic ${ }^{d}$ Snezana Polovina ${ }^{e, f}$ Dragan Micic ${ }^{a, e}$ \\ Ivana Nedeljkovic ${ }^{a}$ b \\ aSchool of Medicine, University of Belgrade, Belgrade, Serbia; ${ }^{b}$ Clinical Center of Serbia, \\ Department of Cardiology, Belgrade, Serbia; ${ }^{C}$ Clinical Center of Serbia, Department of \\ Digestive Surgery, Belgrade, Serbia; ${ }^{\mathrm{d} C e n t r e}$ for Clinical Pharmacology, Faculty of Medicine

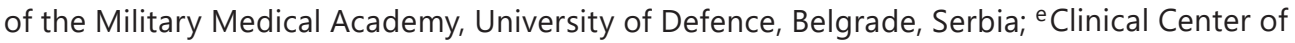 \\ Serbia, Department of Endocrinology, Belgrade, Serbia; ${ }^{f}$ Faculty of Pharmacy, University of \\ Novi Sad, Novi Sad, Serbia
}

\section{Keywords}

Bariatric surgery · Cardiopulmonary exercise test · Roux-en-Y gastric bypass ·

Functional capacity

\begin{abstract}
Background: Bariatric surgery, especially Roux-en-Y gastric bypass (RYGB), has become the most frequently used therapy for morbid obesity. Objectives: The aim of this study was to examine the effects of surgically induced weight loss on cardiopulmonary function 6 months after the procedure, as well as the effect of such an intervention on well-known risk factors for cardiovascular diseases. Methods: This is a cross-sectional study on 66 morbidly obese patients (BMI $\geq 40$ or $\geq 35 \mathrm{~kg} / \mathrm{m}^{2}$ with present comorbidities), comparing their cardiopulmonary function prior to and 6 months after RYGB surgery. Results: The substantial amount of weight loss (29.80 $\pm 13.27 \mathrm{~kg})$ after RYGB surgery was associated with significant reduction of comorbidities, especially diabetes and sedentary lifestyle ( $p=0.005$ and $p=0.002$, respectively). Regarding functional capacity, there was significant increase in peak oxygen uptake $\left(\mathrm{VO}_{2}\right.$ peak, $\left.p=0.003\right)$, duration of exercise testing, metabolic equivalents (exercise time and METs, $p<0.001$ ), and in peak $\mathrm{O}_{2}$ pulse. These findings were particularly pronounced in a group of patients who had lost more than $18 \%$ of initial weight. Conclusions: Reduction of body weight after RYGB surgery is associated with significantly improved cardiorespiratory function
\end{abstract}


Nedeljkovic-Arsenovic et al.: Bariatric Surgery and Cardiopulmonary Function

6 months after surgery, especially in patients who lost more than $18 \%$ of their initial body weight. In addition, substantial decreases in body weight were also associated with a reduction of cardiovascular risk factors such as diabetes, smoking, hypertriglyceridemia, and sedentary lifestyle.

(C) 2019 The Author(s)

Published by S. Karger AG, Basel

\section{Introduction}

Obesity is a leading public health problem in the 21st century [1]. It is a chronic disease caused by excessive fat accumulation in the body and weight gain leading to health disorders, poor quality of life, morbidity, and also it represents financial burden for the healthcare system, especially for developing countries like Serbia [2-5]. Obesity and being overweight are associated with increased total mortality, especially due to cardiovascular disease [6-9].

Roux-en-Y gastric bypass (RYGB) represents one of the most effective surgical options for surgical treatment of obesity [10]. In comparison with nonsurgical treatment, surgery results in more extensive body weight loss, higher remission rates of metabolic syndrome, and better control of comorbidities $[8,11-14]$. The mortality rate after gastric bypass surgery is $0.3-1 \%$, while the morbidity rate is $18.7 \%[13,15,16]$.

Morbid obesity is associated with cardiopulmonary function disorders and with increased risk of cardiovascular disease. Obesity can lead to structural and functional worsening of the cardiovascular and pulmonary system $[17,18]$, as well as a reduction of the oxidative capacity of skeletal muscles [19]. Cardiopulmonary functional capacity provides diagnostic and prognostic information in a wide variety of clinical settings [20,21].

Whereas physical function has been demonstrated to improve within a couple of weeks after bariatric surgery [22], cardiopulmonary functional capacity has not been thoroughly evaluated and compared before and 6 months after bariatric surgery [23-25].

The aim of this study was to examine if significant weight loss that occurs after bariatric surgery is associated with improved cardiopulmonary functional capacity 6 months after the surgical procedure, and if surgically induced weight loss has an effect on existing cardiovascular risk factors.

\section{Materials and Methods}

Type of Study

This is a retrospective cross-sectional study on 96 patients who scheduled for bariatric surgery. Of them, 66 patients fulfilled inclusion and exclusion criteria and were selected for a 6- month follow-up after surgery. All patients underwent cardiopulmonary exercise testing (CPET) before and 6 months after surgical treatment.

\section{Study Participants}

A total of 66 morbidly obese patients (body mass index [BMI] $\geq 40$ or $\geq 35 \mathrm{~kg} / \mathrm{m}^{2}$ with obesity-related health conditions) aged between 20 and 61 years, mostly women (77.3\%), who underwent bariatric surgery were participants of our study. Functional evaluation was performed prior and 6 months after RYGB. All patients were examined at the Clinical Center of Serbia in the Laboratory for CPET. All patients who fulfilled inclusion and exclusion criteria were included after providing signed informed consent (Fig. 1). 


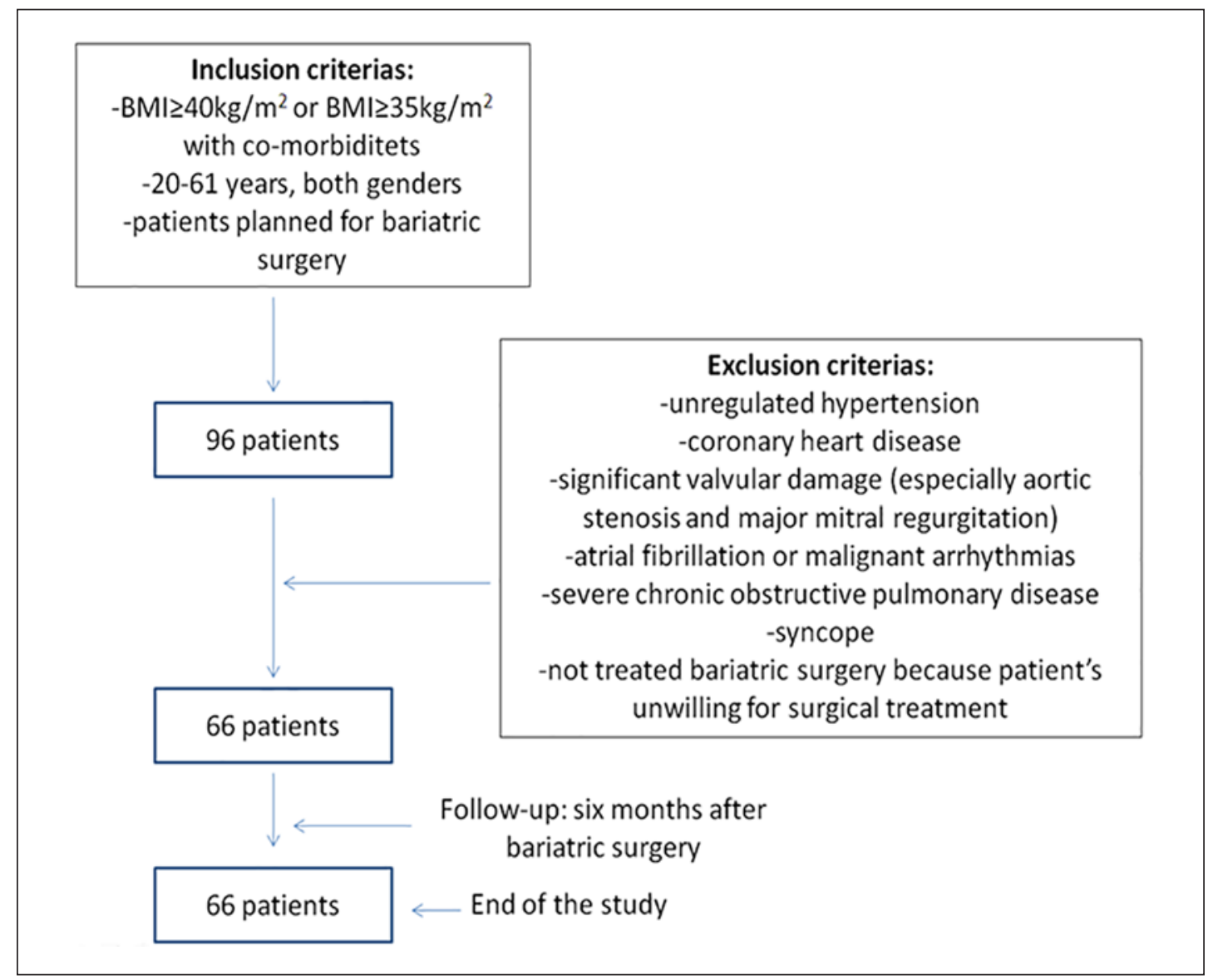

Fig. 1. Flow chart of inclusion and exclusion criteria.

\section{Cardiopulmonary Exercise Testing}

The cardiopulmonary stress test was done on a treadmill using the maximal Bruce protocol with simultaneous breath-by-breath analysis of exchanged gases in the exhaled air through a facial mask. Each patient performed the same test protocol before and after RYGB. All patients had a normal electrocardiogram (ECG) before the test. During stress testing, 12 channel ECG, oxygen uptake $\left(\mathrm{VO}_{2}\right)$ at the first anaerobic threshold (determined according to the V-slope method), as well as peak oxygen uptake (peak $\mathrm{VO}_{2}$ ) were evaluated. Ventilation parameters and breathing reserve were also monitored. Blood pressure and heart rate were measured at the beginning of the stress test, at the end of each loading level, and during recovery. None of the patients had a positive stress test for myocardial ischemia. The CPET was considered maximal when the ratio of carbon dioxide production $\left(\mathrm{VCO}_{2}\right)$ to oxygen consumption $\left(\mathrm{VO}_{2}\right)$ at the end of the test $\left(\mathrm{VCO}_{2} / \mathrm{VO}_{2}=\mathrm{RER}\right)$ was 1.1. After completing CPET, all patients underwent RYGB.

\section{Statistical Analysis}

Complete statistical analysis of data was done using the statistical software package, PASW Statistics $18^{\circledR}$ (SPSS [Hong Kong] Ltd., Hong Kong, China). All variables were presented as frequency of certain categories. The $\chi^{2}$ test was used for analyzing the significance of differences of categorical variables. Continuous variables were presented as means (M) and standard deviation (SD) and range and were compared using the paired samples $t$ test and 
Nedeljkovic-Arsenovic et al.: Bariatric Surgery and Cardiopulmonary Function

Table 1. Anthropometric measures of patients before surgery and 6 months after surgery

\begin{tabular}{lcccc}
\hline & $\begin{array}{l}\text { Before } \\
\text { surgery (A) }\end{array}$ & $\begin{array}{l}\text { Six months after } \\
\text { surgery (B) }\end{array}$ & $p$ value* & $\begin{array}{l}\text { Amount of reduction 6 } \\
\text { months after surgery } \\
\text { (A-B) }\end{array}$ \\
\hline $\mathrm{BM}, \mathrm{kg}$ & $126.92 \pm 19.19$ & $97.12 \pm 17.28$ & $<0.001$ & $29.80 \pm 13.27$ \\
$\mathrm{BSA}, \mathrm{m}^{2}$ & $2.31 \pm 0.21$ & $2.06 \pm 0.20$ & $<0.001$ & $0.25 \pm 0.12$ \\
$\mathrm{BMI}, \mathrm{kg} / \mathrm{m}^{2}$ & $43.75 \pm 5.22$ & $33.78 \pm 6.01$ & $<0.001$ & $9.96 \pm 4.25$ \\
\hline
\end{tabular}

Values are given as mean \pm SD. BM, body mass; BSA, body surface area; BMI, body mass index. * Paired samples $t$ test.

Table 2. Patient distribution before and after surgery according to comorbidities and therapy

\begin{tabular}{lccc}
\hline & $\begin{array}{l}\text { Before } \\
\text { surgery }\end{array}$ & $\begin{array}{l}\text { Six months } \\
\text { after surgery }\end{array}$ & $p$ value* $^{*}$ \\
\hline Comorbidities & & & 0.002 \\
Physical activity & $23(34.8)$ & $42(63.6)$ & 0.860 \\
Hypertension & $29(43.9)$ & $27(40.9)$ & 0.978 \\
COPD & $1(1.5)$ & $2(3.1)$ & 0.932 \\
OSA & $2(3.0)$ & $9(14.1) /-$ & 0.005 \\
DM/IR & $18(27.3) / 6(9.1)$ & $7(10.6)$ & 1.000 \\
Hypercholesterolemia & $6(9.1)$ & $2(3.1)$ & 0.294 \\
Hypertriglyceridemia & $6(9.1)$ & $9(14.1)$ & 0.285 \\
Smoking & $14(21.2)$ & $26(39.4)$ & 1.000 \\
\hline Therapy & $26(39.4)$ & $19(28.8)$ & 0.518 \\
Antihypertensive therapy & $16(24.2)$ & $6(9.4)$ & 0.331 \\
Beta-blockers & $11(16.7)$ & - & 0.227 \\
Ca antagonist & $1(1.5)$ & $10(15.6)$ & - \\
Nitrates & $17(25.8)$ & $9(14.1)$ & 0.007 \\
ACE inhibitors & $5(7.6)$ & $24(36.4)$ & \\
Statins & & & \\
Antidiabetics & & & \\
\hline
\end{tabular}

Values are given as $n(\%)$. COPD, chronic obstructive pulmonary disease; OSA, obstructive sleep apnea syndrome; DM, diabetes mellitus; IR, insulin resistance; ACE inhibitors, angiotensin-converting-enzyme inhibitors; Ca antagonist, calcium channel blockers. ${ }^{*} \chi^{2}$ test.

independent $t$ test. Distribution normality was tested using the Kolmogorov-Smirnov test (the number of subjects was $>50$ ). The level of the statistical significance was estimated at $p<0.05$ for all analyses.

\section{Results}

Anthropometric measures of the group before and after surgery are presented in Table 1. There was a statistically significant reduction of body mass weight (BM), body surface area (BSA), and BMI 6 months after surgery in comparison to the initial values $(p<0.001)$.

Most of the 66 patients had class III obesity (BMI $>40 \mathrm{~kg} / \mathrm{m}^{2} ; n=48$ or $72.7 \%$ ) and the remainder had class II obesity (BMI $35-39.99 \mathrm{~kg} / \mathrm{m}^{2} ; n=17$ or $25.8 \%$ ). Comorbidities related to obesity in those patients were hypertension in $43.9 \%$ patients, diabetes mellitus (DM) in 
Nedeljkovic-Arsenovic et al.: Bariatric Surgery and Cardiopulmonary Function

Table 3. Distribution of patients according to the decrease of body mass $(<18 \%$ and $>18 \%)$ before surgery versus 6 months after bariatric surgery

\begin{tabular}{|c|c|c|c|c|c|c|c|c|}
\hline & \multicolumn{3}{|l|}{$<18 \%$ BM } & \multicolumn{3}{|l|}{$>18 \% \mathrm{BM}$} & \multirow{2}{*}{$\begin{array}{l}\text { Before } \\
\text { surgery }\end{array}$} & \multirow{2}{*}{$\begin{array}{l}\begin{array}{l}\text { Six months } \\
\text { after surgery }\end{array} \\
<18 \% \mathrm{BM} / \\
>18 \% \mathrm{BM} \\
p \text { value** }\end{array}$} \\
\hline & $\begin{array}{l}\text { before } \\
\text { surgery }\end{array}$ & $\begin{array}{l}6 \text { months } \\
\text { after surgery }\end{array}$ & $p$ value* & $\begin{array}{l}\text { before } \\
\text { surgery }\end{array}$ & $\begin{array}{l}6 \text { months } \\
\text { after surgery }\end{array}$ & $p$ value* & & \\
\hline FEV1, L & $3.15 \pm 0.65$ & $3.38 \pm 0.71$ & 0.052 & $2.94 \pm 0.57$ & $3.66 \pm 3.43$ & 0.146 & 0.232 & 0.745 \\
\hline FEV1, \% & $97.50 \pm 12.30$ & $100.44 \pm 12.42$ & 0.219 & $90.26 \pm 14.97$ & $96.88 \pm 15.34$ & $<0.001$ & 0.085 & 0.403 \\
\hline Time to AT, s & $258.75 \pm 104.62$ & $314.37 \pm 131.55$ & 0.055 & $248.33 \pm 92.93$ & $396.04 \pm 123.30$ & $<0.001$ & 0.708 & 0.027 \\
\hline Ex time, s & $398.81 \pm 109.59$ & $446.94 \pm 114.08$ & 0.028 & $361.82 \pm 99.33$ & $517.70 \pm 127.68$ & $<0.001$ & 0.211 & 0.045 \\
\hline Peak $\mathrm{VO}_{2}, \mathrm{~mL} / \mathrm{kg} / \mathrm{min}$ & $20.19 \pm 2.71$ & $22.26 \pm 3.19$ & 0.009 & $21.20 \pm 3.95$ & $26.32 \pm 4.83$ & $<0.001$ & 0.345 & 0.003 \\
\hline METs & $5.64 \pm 0.76$ & $6.36 \pm 0.88$ & 0.008 & $6.08 \pm 1.06$ & $7.48 \pm 1.33$ & $<0.001$ & 0.160 & 0.003 \\
\hline Peak $\mathrm{VO}_{2}, \mathrm{~mL} / \mathrm{min}$ & $2.62 \pm 0.43$ & $2.58 \pm 0.43$ & 0.708 & $2.62 \pm 0.49$ & $2.40 \pm 0.51$ & $<0.001$ & 0.955 & 0.174 \\
\hline $\mathrm{HR}$ at $\mathrm{AT}$, beat $/ \mathrm{min}$ & $143.31 \pm 16.86$ & $136.56 \pm 22.90$ & 0.197 & $152.30 \pm 16.83$ & $144.80 \pm 16.46$ & $<0.006$ & 0.068 & 0.120 \\
\hline Peak $\mathrm{O}_{2}$ pulse, $\mathrm{mL} /$ beat & $17.76 \pm 3.82$ & $17.75 \pm 3.96$ & 0.996 & $17.21 \pm 4.43$ & $14.87 \pm 3.03$ & $<0.001$ & 0.662 & 0.003 \\
\hline MaxSBP, mm Hg & $182.19 \pm 18.11$ & $165.31 \pm 23.57$ & 0.054 & $183.70 \pm 28.15$ & $164.30 \pm 24.97$ & $<0.001$ & 0.841 & 0.887 \\
\hline MaxDBP, mm Hg & $101.44 \pm 8.95$ & $94.69 \pm 9.59$ & 0.010 & $97.56 \pm 12.05$ & $92.58 \pm 10.24$ & $<0.016$ & 0.241 & 0.470 \\
\hline Max VE, L/min & $69.28 \pm 12.97$ & $63.87 \pm 18.79$ & 0.213 & $67.36 \pm 12.92$ & $63.18 \pm 15.77$ & $<0.021$ & 0.606 & 0.886 \\
\hline $\mathrm{BR}, \%$ & $37.94 \pm 11.51$ & $42.13 \pm 10.93$ & 0.174 & $35.84 \pm 14.68$ & $41.70 \pm 12.09$ & $<0.007$ & 0.604 & 0.901 \\
\hline $\mathrm{VE} / \mathrm{VCO}_{2}$ slope & $26.18 \pm 5.07$ & $23.82 \pm 2.63$ & 0.080 & $26.96 \pm 4.75$ & $24.79 \pm 4.14$ & $<0.003$ & 0.580 & 0.381 \\
\hline $\mathrm{PETCO}_{2}, \mathrm{~mm} \mathrm{Hg}$ & $36.25 \pm 5.30$ & $34.76 \pm 3.87$ & 0.788 & $36.91 \pm 4.91$ & $31.48 \pm 4.46$ & $<0.010$ & 0.813 & 0.565 \\
\hline RER & $1.02 \pm 0.07$ & $1.07 \pm 0.06$ & 0.035 & $1.01 \pm 0.07$ & $1.07 \pm 0.06$ & $<0.001$ & 0.806 & 0.871 \\
\hline
\end{tabular}

Values are given as mean $\pm \mathrm{SD}$. BM, body mass; FEV1, forced expiratory volume in the first second; Peak VO $\mathrm{V}_{2}$, oxygen uptake at maximal effort; AT, anaerobic threshold; EX time, exercise time; METs, metabolic equivalents of task; VE/ $\mathrm{VCO}_{2}$ slope, ventilatory efficiency; VE, minute ventilation; $\mathrm{BR}$, breathing reserve; PETCO partial pressure of end-tidal carbon dioxide; SBP, systolic blood pressure; DBP, diastolic blood pressure; RER, respiratory exchange ratio; HR at AT, heart rate at first anaerobic threshold. * Paired samples $t$ test. ${ }^{* *}$ Independent $t$ test.

Fig. 2. Number of antihypertensive drugs before and 6 months after bariatric surgery.

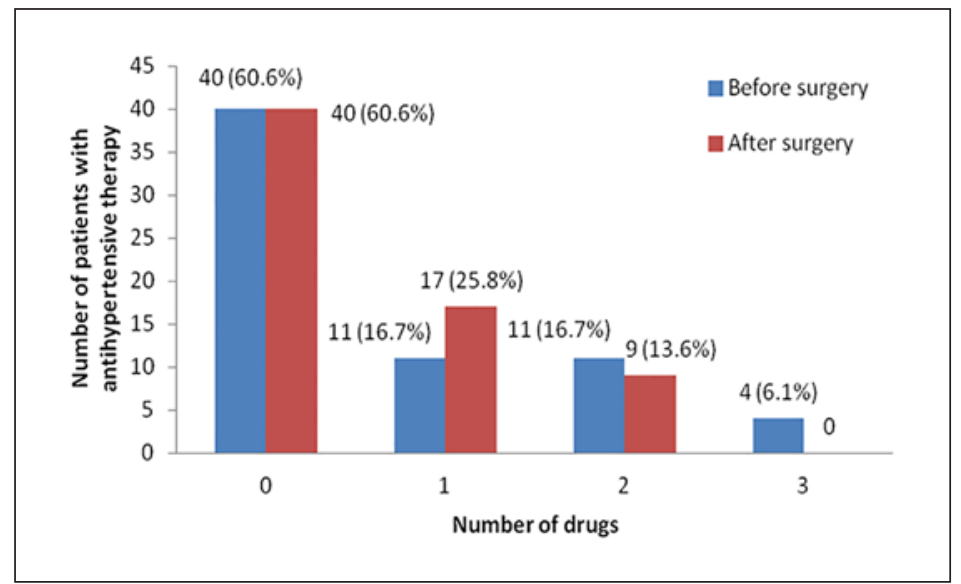

27.3\%, insulin resistance in 9.1\%, and obstructive sleep apnea in 3.0\%. Most patients were sedentary before surgery (65.2\%). All patients with hypertension took antihypertensive therapy including angiotensin-converting enzyme inhibitors (ACE inhibitors) in 25.8\%, betablockers in $24.2 \%$, calcium channel blockers (Ca antagonists) in $16.7 \%$, and nitrates in $1.5 \%$. Furthermore, $36.4 \%$ of patients had oral therapy for DM. Six of the patients $(9.1 \%)$ who underwent bariatric surgery had hypertriglyceridemia and hypercholesterolemia, 5 of them were taking statins before intervention.

With respect to the accompanying comorbidities, there was significant clinical improvement in DM and obstructive sleep apnea syndrome 6 months after surgery (Table 2). Most of the patients become more physically active (63.6\%). In addition, there was a reduction 
Fig. 3. Average of peak $\mathrm{VO}_{2}$ in patients with bariatric surgery according to decrease of $\mathrm{BM}(<18$ and $>18 \%$ ) before versus 6 months after bariatric surgery.

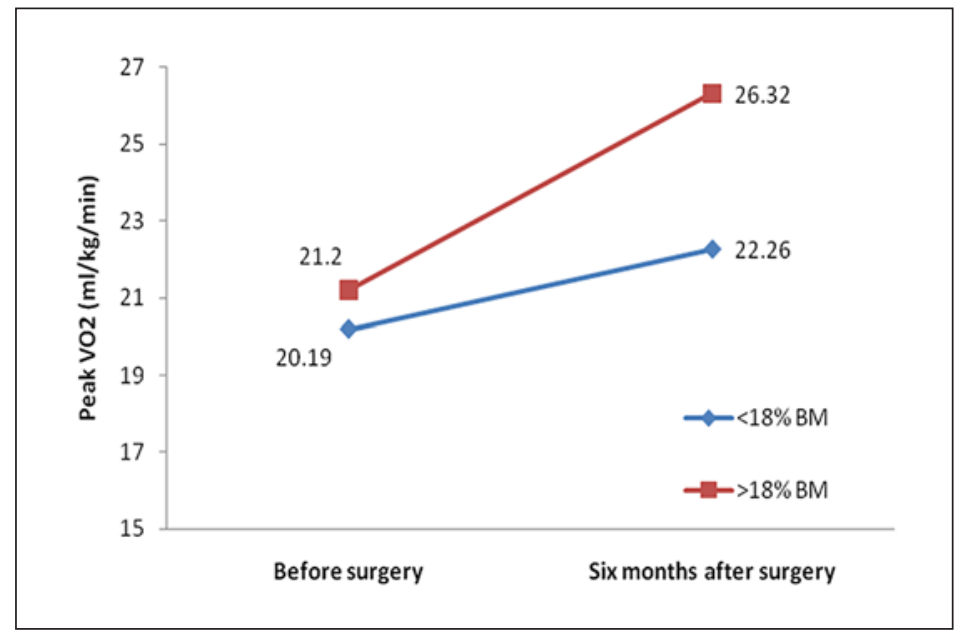

in the use of drugs for hypertension. Although the same number of patients (29 subjects) were using pharmacotherapy for hypertension after surgery, only 9 patients were using dual therapy. Before surgery, 11 patients were using dual therapy and 4 patients were using triple antihypertensive therapy (Fig. 2). Also, after surgery only 9 of 26 patients with preoperative DM continued to take medications for DM $(p=0.007)$. None of the patients continued to use statins after intervention.

Furthermore, we investigated the extent of weight loss that was associated with significant improvement in CPET parameters. Patients who lost more than $18 \%$ of their initial weight had significantly better CPET results 6 months after the surgery (Table 3). Comparing relative peak oxygen uptake $\left(\mathrm{VO}_{2}\right.$ peak/kg), there were important differences between the two groups $(p=0.003)$ after surgical treatment. In both groups, peak $\mathrm{VO}_{2}$ per body weight was significantly increased after RYGB ( $p=0.009$ and $p<0.001$, respectively) (Fig. 3). However, the absolute $\mathrm{VO}_{2}$ peak was unchanged in those who had a $<18 \%$ BM reduction, while there was a significant decrease in $\mathrm{VO}_{2}$ peak after 6 months in those who had a $>18 \%$ $\mathrm{BM}$ reduction ( $p=0.708$ and $p=0.001$, respectively). In addition, exercise duration time was significantly longer in the group of patients who lost more than $18 \%$ of their initial weight. Also, ventilatory efficiency and breathing reserve were significantly better after surgery in patients with greater BM reduction (Table 3).

\section{Discussion}

In contrast to previous studies of cardiovascular outcomes after bariatric surgery [26, 27], which demonstrated physical capacity improvement on ergo bicycle, we have shown amelioration of cardiorespiratory functional parameters using a treadmill test. This is an important difference in study design, since walking is the most natural and most commonly reported mode of physical activity among patients. In general, in all patients, bariatric surgery brought certain improvement in cardiorespiratory function. Regarding the respiratory exchange ratio (RER), our study demonstrated significantly higher RER 6 months after surgery suggesting achievement of higher intensity of activity after greater loss of kilograms, but with no statistical difference among groups. This ratio was earlier reported in only three studies, showing an increase in two and no change in the other study $[24,25,28]$.

However, our study is unique in that we suggest that an $18 \%$ reduction of initial weight after surgery is associated with statistically significant improvement in cardiorespiratory 
Nedeljkovic-Arsenovic et al.: Bariatric Surgery and Cardiopulmonary Function

parameters. Previous studies have also investigated CPET parameters 3-12 months after sleeve gastrectomy or gastric bypass surgery [11, 24, 29-31]. To our knowledge, this is the first study which has correlated the amount of weight loss that is needed to result in improvement of aerobic capacity. A study by MacMahon et al. [32] showed that weight loss of as little as $8 \mathrm{~kg}$ is associated with a significant decrease in left ventricular mass after 6 months, while Alpert et al. [33] demonstrated that cardiac function in morbidly obese individuals improved with an average weight loss of $55 \mathrm{~kg}$. However, few studies performed a 6-min walk test for estimation of exercise capacity [34].

Peak $\mathrm{VO}_{2}$ representing the highest achieved oxygen consumption during the cardiovascular stress test is the most often analyzed parameter for cardiorespiratory fitness assessment. A weight loss of $18 \%$ of initial kilograms after surgery was associated with significant differences between groups regarding relative oxygen consumption, suggesting improvement in aerobic capacity. However, more evidence is needed regarding mechanisms involved in that improvement. Improved aerobic capacity may be due to better efficiency in performing activities rather than real improvements in cardiorespiratory or muscle function. Even though an increase of $\mathrm{VO}_{2}$ peak per body weight $(\mathrm{mL} / \mathrm{min} / \mathrm{kg})$ confirmed better physical functioning and mobility [29-31], absolute aerobic capacity in terms of $\mathrm{VO}_{2}$ peak $(\mathrm{mL} / \mathrm{min})$ was unchanged after bariatric surgery. Nevertheless, in the group which had more than $18 \%$ weight reduction, $\mathrm{VO}_{2}$ peak $(\mathrm{mL} / \mathrm{min})$ was significantly reduced after surgery. Thus, improvement of physical functioning in patients after bariatric surgery is more a mechanical phenomenon of consequential weight loss than an absolute improvement of cardiopulmonary and muscle function [35]. Therefore, the risk of poor cardiorespiratory and muscle function may persist postsurgically in patients despite their weight loss.

According to preceding studies, the absolute $\mathrm{VO}_{2}$ peak was unchanged (at the 12- and 27-month follow-up) [24, 25] or reduced (at the 6-month follow-up) [28] after bariatric surgery, which is similar to our findings. Peak $\mathrm{VO}_{2}$ relative to body weight was importantly increased in all studies where it was reported [23-25,28], but without indicating the amount of weight loss that is significant. In addition, in previous studies major postoperative increases in physical activity were seen after sleeve gastrectomy, and these findings were associated with greater weight loss and improved quality of life [36, 37]. The same outcome was observed in our study population but after RYGB surgery. About $64 \%$ of patients become physically active, as defined by having daily walks of a minimum of $1 \mathrm{~h}$ by self-report, so physical exercise pre- and postoperation might be recommended as a beneficial add-on therapy to bariatric surgery. Furthermore, we showed significant amelioration of peak $\mathrm{O}_{2}$ pulse among groups after surgery. This result is different from previous reports in which peak $\mathrm{O}_{2}$ pulse did not change 2 months after surgery [26, 27] and was not different between lean and obese individuals during treadmill exercise $[24,38]$. Patients who had $>18 \%$ weight reduction also had significant improvement in peak $\mathrm{O}_{2}$ pulse compared to those with less weight reduction.

Abnormalities in exercise ventilation usually give useful explanation of pathophysiology of dyspnea, lung gas exchange, and control of ventilation. Currently, these types of measurements are recognized as meaningful indicators of disease severity and prognosis. In our study, we did not find differences among groups after surgery regarding ventilatory parameters. However, substantial weight loss should lead to an improvement in all ventilatory parameters including FEV1, breathing reserve, ventilatory efficiency, minute ventilation at peak exercise and $\mathrm{PETCO}_{2}$ after 6 months. Similar to a study by Kanoupakis et al. [28], our study showed a decrease in minute ventilation at peak exercise $(p=0.021) 6$ months after bariatric surgery that might be explained by mechanical facilitation in filling the lungs' alveoli after sufficient weight loss $[39,40]$. Meanwhile, our data suggests that weight reduction of less than $18 \%$ is not associated with any statistically significant improvement of ventilatory function. 
Nedeljkovic-Arsenovic et al.: Bariatric Surgery and Cardiopulmonary Function

Our study has found that the substantial decrease of body weight and BMI that occurs after bariatric surgery is associated with a reduction of cardiovascular risk factors such as DM, smoking, hypertriglyceridemia, as well as on the sedentary lifestyle. In addition, the number of used drugs for DM and arterial hypertension was considerably reduced. From the perspective of the patients' quality of life, as well as from the economic point of view [3, 4, 41-43], this could be a very important finding. However, larger studies with higher number of patients are needed to further analyze these data. Nevertheless, we demonstrated that significant weight loss after RYGB improves daily physical activities and has a positive impact on accompanying comorbidities and existing cardiovascular risk factors $[8,9,13,16,31$, 44-46]. In addition to morbidity and premature mortality, obesity and physical inactivity are responsible for a large economic burden [47].

\section{Conclusion}

This study of cardiovascular and respiratory outcomes after bariatric surgery demonstrates the beneficial effects of surgical weight reduction on patients' health and functional capacity. In addition, we demonstrated that an $18 \%$ reduction of initial body weight may be a threshold value that is critical for significantly better aerobic capacity and other cardiorespiratory outcomes after bariatric surgery.

\section{Limitations}

The number of subjects evaluated is relatively small to assess patients based on age groups in terms of comparing $\mathrm{VO}_{2}$ max. We did not perform echocardiographic evaluations in our study, and, as a result, we were unable to compare stroke volume and cardiac output before and after RYGB. Our study population was predominantly female, so future studies including male participants are needed to expand upon the current findings in order to better understand how bariatric surgery may impact cardiorespiratory capacity and exercise tolerance in men. It is known that $\mathrm{VO}_{2}$ depends on sex, age, and physical fitness. We did not have a more adequate tool to measure physical activity in patients, such as by using an actigraphy device, and relied only on patient self-report.

Findings of this observational study should be confirmed by randomized controlled trials with a large sample size. Also, it is necessary to monitor these patients longer in order to evaluate the long-term effects of this surgical method on body weight loss, comorbidities, and quality of life.

\section{Acknowledgement}

The authors would like to express their gratitude to the Ministry of Education, Science and Technological Development of the Republic of Serbia for Grant No. 41022.

The authors would like to express their gratitude to Srdjan Nedeljkovic, MD, Assistant Professor at Harvard Medical School, Brigham and Women's Hospital, for critically reading the draft versions of this article, as well as for improving the English language.

\section{Statement of Ethics}

All patients have given their written informed consent. The study protocol has been approved by the local Ethical Committee on human research. 
Nedeljkovic-Arsenovic et al.: Bariatric Surgery and Cardiopulmonary Function

The principles of ICH Good Clinical Practice were strictly followed and ethical approval from the Ethics Committee of the Clinical Center Serbia was obtained for the study protocol under the number 318/6 on May 18th, 2017.

\section{Disclosure Statement}

The authors have no conflicts of interest to declare.

\section{References}

1 Flegal KM, Carroll MD, Ogden CL, Curtin LR. Prevalence and trends in obesity among US adults, 1999-2008. JAMA. 2010 Jan;303(3):235-41.

2 World Health Organisation. The European health report 2015. Targets and beyond - Reaching new frontiers in evidence. Copenhagen: WHO Regional Office for Europe; 2015 [cited 2018 Feb 29]. Available from: http:// www.euro.who.int/_data/assets/pdf_file/0006/288645/European-health-report-2015-full-book-en. pdf?ua $=1$.

3 Biorac N, Jakovljević M, Stefanović D, Perović S, Janković S. Assessment of diabetes mellitus type 2 treatment costs in the Republic of Serbia. Vojnosanit Pregl. 2009 Apr;66(4):271-6. Serbian.

4 Jakovljevic M, Jovanovic M, Lazic Z, Jakovljevic V, Djukic A, Velickovic R, et al. Current efforts and proposals to reduce healthcare costs in Serbia. Serb J Exp Clin Res. 2011;12(4):161-3.

5 Jakovljevic M. Health expenditure dynamics in Serbia 1995-2012. Hospital Pharmacology. 2014;1(3):180-3.

6 Alpert MA, Omran J, Bostick BP. Effects of obesity on cardiovascular hemodynamics, cardiac morphology, and ventricular function. Curr Obes Rep. 2016 Dec;5(4):424-34.

7 Mark DH. Deaths attributable to obesity. JAMA. 2005 Apr;293(15):1918-9.

8 Di Angelantonio E, Bhupathiraju SN, Wormser D, Gao P, Kaptoge S, Berrington de Gonzalez A, et al.; Global BMI Mortality Collaboration. Body-mass index and all-cause mortality: individual-participant-data meta-analysis of 239 prospective studies in four continents. Lancet. 2016 Aug;388(10046):776-86.

9 Duncan M, Griffith M, Rutter H, Goldacre MJ. Certification of obesity as a cause of death in England 1979-2006. Eur J Public Health. 2010 Dec;20(6):671-5.

10 DeMaria EJ. Bariatric surgery for morbid obesity. N Engl J Med. 2007 May;356(21):2176-83.

11 Neunhaeuserer D, Gasperetti A, Savalla F, Gobbo S, Bullo V, Bergamin M, et al. Functional Evaluation in Obese Patients Before and After Sleeve Gastrectomy. Obes Surg. 2017 Dec;27(12):3230-9.

12 Ribaric G, Buchwald JN, McGlennon TW. Diabetes and weight in comparative studies of bariatric surgery vs conventional medical therapy: a systematic review and meta-analysis. Obes Surg. 2014 Mar;24(3):437-55.

13 Gloy VL, Briel M, Bhatt DL, Kashyap SR, Schauer PR, Mingrone G, et al. Bariatric surgery versus non-surgical treatment for obesity: a systematic review and meta-analysis of randomised controlled trials. BMJ. 2013 Oct; 347 oct22 1:f5934.

14 Jakovljevic MB, Milovanovic O. Growing Burden of Non-Communicable Diseases in the Emerging Health Markets: the Case of BRICS. Front Public Health. 2015 Apr;3:65-70.

15 Bjelović M, Veselinović M. Roux-en-Y gastric bypass. In: Bjelovic M, Polovina M, editors. Surgical treatment of obesity: from bariatric to metabolic surgery. Belgrade: CIBID; 2016. pp. 151-73.

16 Okunade AA, Rubin RM, Okunade AK. Delayed Effects of Obese and Overweight Population Conditions on AllCause Adult Mortality Rate in the USA. Front Public Health. 2016 Sep;4:212-21.

17 Hsuan CF, Huang CK, Lin JW, Lin LC, Lee TL, Tai CM, et al. The effect of surgical weight reduction on left ventricular structure and function in severe obesity. Obesity (Silver Spring). 2010 Jun;18(6):1188-93.

18 Xavier MA, Ceneviva R, Terra Filho J, Sankarankutty AK. Pulmonary function and quality of life in patients with morbid obesity six months after bariatric surgery. Acta Cir Bras. 2010 Oct;25(5):407-15.

19 Coen PM, Hames KC, Leachman EM, DeLany JP, Ritov VB, Menshikova EV, et al. Reduced skeletal muscle oxidative capacity and elevated ceramide but not diacylglycerol content in severe obesity. Obesity (Silver Spring). 2013 Nov;21(11):2362-71.

20 Fleg JL, Piña IL, Balady GJ, Chaitman BR, Fletcher B, Lavie C, et al. Assessment of functional capacity in clinical and research applications: An advisory from the Committee on Exercise, Rehabilitation, and Prevention, Council on Clinical Cardiology, American Heart Association. Circulation. 2000 Sep;102(13):1591-7.

21 Nedeljkovic I, Banovic M, Stepanovic J, Giga V, Djordjevic-Dikic A, Trifunovic D, et al. The combined exercise stress echocardiography and cardiopulmonary exercise test for identification of masked heart failure with preserved ejection fraction in patients with hypertension. Eur J Prev Cardiol. 2016 Jan;23(1):71-7.

22 Dymek MP, Le Grange D, Neven K, Alverdy J. Quality of life after gastric bypass surgery: a cross-sectional study. Obes Res. 2002 Nov;10(11):1135-42. 
Nedeljkovic-Arsenovic et al.: Bariatric Surgery and Cardiopulmonary Function

23 de Souza SA, Faintuch J, Sant'anna AF. Effect of weight loss on aerobic capacity in patients with severe obesity before and after bariatric surgery. Obes Surg. 2010 Jul;20(7):871-5.

24 Serés L, Lopez-Ayerbe J, Coll R, Rodriguez O, Vila J, Formiguera X, et al. Increased exercise capacity after surgically induced weight loss in morbid obesity. Obesity (Silver Spring). 2006 Feb;14(2):273-9.

25 Wilms B, Ernst B, Thurnheer M, Weisser B, Schultes B. Differential changes in exercise performance after massive weight loss induced by bariatric surgery. Obes Surg. 2013 Mar;23(3):365-71.

26 Zavorsky GS, Kim DJ, Christou NV. Compensatory exercise hyperventilation is restored in the morbidly obese after bariatric surgery. Obes Surg. 2008 May;18(5):549-59.

27 Stegen S, Derave W, Calders P, Van Laethem C, Pattyn P. Physical fitness in morbidly obese patients: effect of gastric bypass surgery and exercise training. Obes Surg. 2011 Jan;21(1):61-70.

28 Kanoupakis E, Michaloudis D, Fraidakis O, Parthenakis F, Vardas P, Melissas J. Left ventricular function and cardiopulmonary performance following surgical treatment of morbid obesity. Obes Surg. 2001 Oct;11(5):552-8.

29 Browning MG, Franco RL, Herrick JE, Arrowood JA, Evans RK. Assessment of cardiopulmonary responses to treadmill walking following gastric bypass surgery. Obes Surg. 2017 Jan;27(1):96-101.

30 Vargas CB, Picolli F, Dani C, Padoin AV, Mottin CC. Functioning of obese individuals in pre- and postoperative periods of bariatric surgery. Obes Surg. 2013 Oct;23(10):1590-5.

31 Miller GD, Nicklas BJ, You T, Fernandez A, Fernandez A. Physical function improvements after laparoscopic Roux-en-Y gastric bypass surgery. Surg Obes Relat Dis. 2009 Sep-Oct;5(5):530-7.

32 MacMahon SW, Wilcken DE, Macdonald GJ. The effect of weight reduction on left ventricular mass. A randomized controlled trial in young, overweight hypertensive patients. N Engl J Med. 1986 Feb 6;314(6): 334-9.

33 Alpert MA, Terry BE, Kelly DL. Effect of weight loss on cardiac chamber size, wall thickness and left ventricular function in morbid obesity. Am J Cardiol. 1985 Mar;55(6):783-6.

34 da Silva RP, Martinez D, Faria CC, de Carli LA, de Souza WI, Meinhardt NG, et al. Improvement of exercise capacity and peripheral metaboreflex after bariatric surgery. Obes Surg. 2013 Nov;23(11):1835-41.

35 Steele T, Cuthbertson DJ, Wilding JP. Impact of bariatric surgery on physical functioning in obese adults. Obes Rev. 2015 Mar;16(3):248-58.

36 Egberts K, Brown WA, Brennan L, O’Brien PE. Does exercise improve weight loss after bariatric surgery? A systematic review. Obes Surg. 2012 Feb;22(2):335-41.

37 Bond DS, Phelan S, Wolfe LG, Evans RK, Meador JG, Kellum JM, et al. Becoming physically active after bariatric surgery is associated with improved weight loss and health-related quality of life. Obesity (Silver Spring). 2009 Jan;17(1):78-83.

38 Ohrström M, Hedenbro J, Ekelund M. Energy expenditure during treadmill walking before and after vertical banded gastroplasty: a one-year follow-up study in 11 obese women. Eur J Surg. 2001 Nov;167(11):845-50.

39 Refsum HE, Holter PH, Løvig T, Haffner JF, Stadaas JO. Pulmonary function and energy expenditure after marked weight loss in obese women: observations before and one year after gastric banding. Int J Obes. 1990 Feb;14(2):175-83.

40 Babb TG, Korzick D, Meador M, Hodgson JL, Buskirk ER. Ventilatory response of moderately obese women to submaximal exercise. Int J Obes. 1991 Jan;15(1):59-65.

41 Seidell JC. Societal and personal costs of obesity. Exp Clin Endocrinol Diabetes. 1998;106(2 Suppl 2):7-9.

42 Tsai AG, Williamson DF, Glick HA. Direct medical cost of overweight and obesity in the USA: a quantitative systematic review. Obes Rev. 2011 Jan;12(1):50-61.

43 The Guardian. Global cost of obesity-related illness to hit \$1.2tn a year from 2025; [cited 2018 Feb 29] Available from: www.theguardian.com/society/2017/oct/10/treating-obesity-related-illness-will-cost12tn-a-year-from-2025-experts-warn.

44 King WC, Chen JY, Belle SH, Courcoulas AP, Dakin GF, Elder KA, et al. Change in pain and physical function following bariatric surgery for severe obesity. JAMA. 2016 Apr;315(13):1362-71.

45 Frühbeck G. Bariatric and metabolic surgery: a shift in eligibility and success criteria. Nat Rev Endocrinol. 2015 Aug;11(8):465-77.

46 Catheline JM, Bihan H, Le Quang T, Sadoun D, Charniot JC, Onnen I, et al. Preoperative cardiac and pulmonary assessment in bariatric surgery. Obes Surg. 2008 Mar;18(3):271-7.

47 Ding D, Lawson KD, Kolbe-Alexander TL, Finkelstein EA, Katzmarzyk PT, van Mechelen W, et al.; Lancet Physical Activity Series 2 Executive Committee. The economic burden of physical inactivity: a global analysis of major non-communicable diseases. Lancet. 2016 Sep;388(10051):1311-24. 